\title{
Negotiation styles between Pakistan and USA: A compar- ative study
}

\author{
Shakil Adnan Malik ${ }^{1 *}$, Barza Iftikhar Mir ${ }^{2}$ \\ ${ }^{1,2}$ COMSATS University, Wah Campus, Islamabad, Pakistan
}

\section{Keywords \\ Negotiation \\ Negotiation styles \\ Pakistani and USA culture \\ Business negotiations \\ effective negotiations}

Received: 4 September 2019

Accepted: 6 November 2019

Published: 12 March 2020

\begin{abstract}
This paper gives a general overview of the essence of negotiations itself, their styles while narrowing down focus on negotiation styles pursued by Americans and Pakistanis. The data is derived from the journals, websites, social reports of the United States, and research papers published. Meta-analysis is used to pool the results of selected studies. The papers related to negotiations in general and those focusing on the negotiation styles of Pakistanis and Americans were utilized, while papers covering the negotiation styles of other countries were excluded from the review. Results highlight that Americans have little understanding of other cultures and are impatient listeners. Being result-oriented, they prefer competing and aggressive styles while adopting the direct approach in negotiation, thereby bypassing the long-term relationship, sacrificing individual interests, and preventing emotions from influencing the negotiation process. However, Pakistani negotiators prefer collaborating and compromising styles. They employ emotions and personal relationships while negotiating. Pakistani negotiators, unlike their American counterparts, focus on the long-term relationship. They employ indirect communication channels and rely on assumption instead of realism. Provided that the world has turned into a global village and business dealings are being carried out across the borders, the findings of this research would be beneficial for traders, expatriates, and employees of multinational corporations.
\end{abstract}

(C) 2020 The Author(s). Published by TAF Publishing

\section{INTRODUCTION}

The faculties of intellect, reasoning and speech make humans superior to other creatures. These faculties are employed in panoramically different ways for personal, individual, organizational, community and societal benefits. This paper specifically deals with negotiation, a skill based on human characteristics of intellect, reasoning and speech. Negotiations are tools for dispute resolution and elimination of irritants and bottlenecks impacting the convergence and similarities of views on a certain issue, dispute, mutuality of understanding thereof. Negotiations are therefore imperatives to reach a common ground as a win-win situation for the parties involved.

In the world rife with disputes at personal, community, countries level and with a market based economy the role of negotiations and negotiators have assumed more impor- tant dimensions. Success or failure of negotiations whether at individual, community, organization or state level is firmly anchored in the quality of negotiations and the skills, knowledge, courage, consistency, clarity of vision and patience of negotiators.

Further, another important aspect of successful negotiations is the style of negotiator since an undiplomatic, unaccommodating, rigid, inflexible, unyielding and self centered stance can lead to collapse of negotiations. Commonly, five elements constitute negotiations' styles that are avoiding, accommodating, compromising, collaborating and competing. Culture is a direct factor in negotiations and affects cross-cultural relations. A complex and globalized world asks for understanding for multiple cultural differences (Caputo, Ayoko, Amoo, \& Menke, 2019).

This research paper specifically focuses on quality and

\footnotetext{
* corresponding author: Shakil Adnan Malik

†email: shakiladnanmalik@ciitwah.edu.pk
} 
styles of negotiations pursued by Pakistani and American negotiators. Quality and styles of negotiations are predominantly determined and shaped by the cultural background, economics and military strength while ethnic and social diversities lend to add opportunities to engage in negotiations leading to further polishing of negotiation skills and confidence since people from different cultural backgrounds have different perceptions on issues relating to their routines. These findings covering American style of negotiations are amply supported by the research studies conducted in the past. Scholar such as Fisher, Ury, and Patton (2011), Lewicki, Saunders, and Barry (2006), Ury (1993), Ury (2007), made enormous contributions as evident from their respective publications on the subject.

Unprecedented globalization of business has brought different communities into closer interaction thereby requiring each segment, region and community to rely on added abilities and energies to work together and engage others for greater cooperation and sustainable relationship. Therefore understanding behavioral patterns and styles of conduct to influence effective interaction is all the more important since necessary realignment of strategies can be done for sustainable engagement:

This research paper aimed at:-

- Providing concise understanding negotiation.

- Providing information on negotiation styles.

- Touching upon the styles of negotiation employed in Pakistan \& America.

- Bringing out similarities and dissimilarities in negotiation styles pursued between Pakistani and American negotiators through contrasting and comparing.

With a reasonable understanding of negotiation, its different styles and the styles in vogue in Pakistan and America individuals requiring engaging with these two countries will be adequately equipped to strategize their negotiations for effective and fruitful outcome. Since this research paper is essentially restricted to the styles of negotiations prevalent in Pakistan and America, thus the relevant information is derived from the material in books, journals, organizational websites, blogs, research papers and magazines published over the past.

The paper contains three parts namely front part, body and end matter. The front matter includes cover page, table of contents and abstract while the body matter consists of five sections containing introduction, literature review, dis- cussion, conclusion, recommendations and limitations. Introduction deals with negotiation as variable, negotiation styles and styles used in the countries of focus that is Pakistan and America. The segment dealing with literature review encompasses critical review of the past studies while discussion is focused on evaluation of studies conducted in the past with a view to make out similarities and dissimilarities between negotiation styles used in Pakistan and USA. Likewise, in the fourth section recommendations are followed by conclusion to give finishing touch to the research paper. The last segment is limitations and future research indication. References of material benefited from during the research study form the last part.

\section{REVIEW OF LITERATURE}

Negotiation is a method by which people settle differences (Hüffmeier et al., 2019). It is a process by which compromise or agreement is reached while avoiding argument and dispute. In any disagreement, individuals understandably aim to achieve the best possible outcome for their position or perhaps an organization they represent. However, the principles of fairness, seeking mutual benefit and maintaining a relationship are the keys to a successful outcome. Specific forms of negotiation are used in many situations: international affairs, legal system, government, industrial disputes or domestic relationships as examples. However, general negotiation skills can be learned and applied in a wide range of activities. Negotiation skills can be of great benefit in resolving differences that arise between individual, groups and communities. Understanding cultural differences effectively assists parties to navigate the negotiations respectfully. Culture impacts the decision-making process and helps to decide if the other party is to be trusted or not. Americans are more inclined towards openness and Pakistanis leans towards respect. Negotiation styles all depend on how loose or tight culture is (Mitchell, 2020).

Negotiation is essentially aimed at finding and learning about the possibilities and prospects of mutual agreement, interaction subsequent to leveling out differences as well as removing irritants for dispute and conflict resolution through compromise. Negotiation is further defined by breaking it into four parts that are resolution, conflict, mutual and compromise (McCarthy \& Hay, 2015; Manager, 2017). Figure 1 further defines it as "resolution of conflict by mutual compromise". 


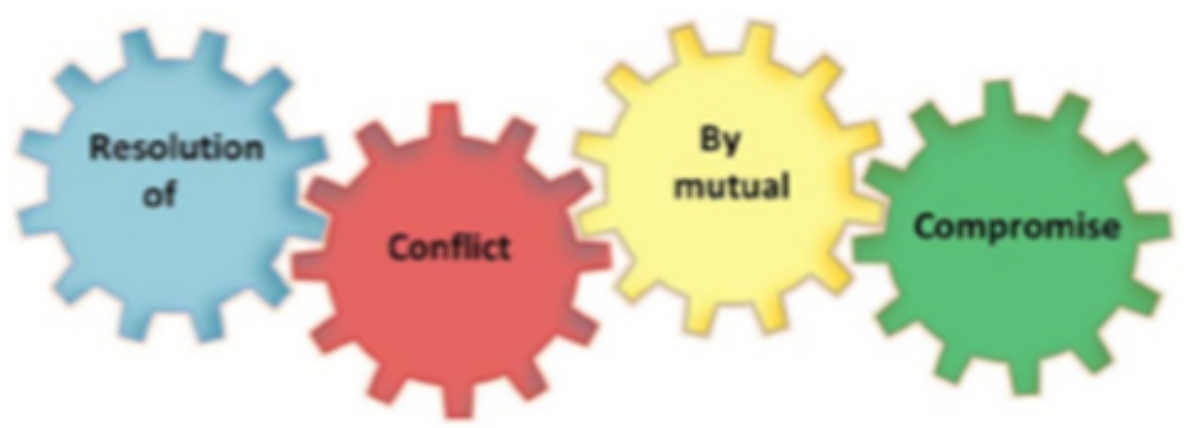

FIGURE 1. Definition of negotiation

Resolution points to the position where parties engaged in negotiations will have a sense of satisfaction that their interests are served. This also points to the fact that all parties are in a win-win situation. Win-win outcome is usually the best outcome yet it by and large depends on the attitudes of parties engaged in negotiations. Nevertheless winwin outcome should be the ultimate goal for all concerned (McCarthy \& Hay, 2015).

Conflict is a situation or state wherein individuals and parties refuse to reconsider their stance on an issue under debate. They are entrenched in their respective positions and are not willing to budge an inch from their stated position. They resolve not to give concession. For instance a buyer tells seller that he does not need a certain product presently or the product offered is expensive. Hence, both parties can be said to have been locked in a conflict (McCarthy \& Hay, 2015; Pan \& Lu, 2019; Raditya, 2018).

Mutual is essentially the spirit of reciprocity, a feeling or an action experienced or done by two or more parties thus it is shared by all concerned. In the immediate context it means that parties involved in negotiations should come to a joint solution where they can be equal beneficiaries of outcome. Mutuality, however, cannot be divorced from the spirit of accommodation. That is if parties concerned are bent upon advancing their individual or respective organizational goals at the expense of their counterparts in the negotiations then the spirit of mutuality is effectively sidelined by marring the prospects of reaching a common ground (McCarthy \& Hay, 2015).

Compromise means to settle for less than initially planned. In order to reach a shared, joint outcome parties and individuals engaged in negotiations are required to realign their respective stances by granting concessions. Differences are essentially sharp edges and impede the ways to reach an understanding. Therefore these sharp edges need to be blunted through reciprocity, compromise and a spirit of accommodation to save the process of negotiation from a total collapse. When each party appreciates the sensitiv- ities of other and resolves to address them this adjustment and magnanimity paves the way leading to final settlement (McCarthy \& Hay, 2015). Since negotiation is an instrument either to resolve a dispute or to produce agreement upon a course of action to bargain individual or collective advantage is to carve out outcomes to satisfy divergent interests. Hence negotiation necessitates among parties engaged in negotiation a spirit of give and take that more than often springs from the fountainhead of compromise (Singh, 2008).

\section{Negotiation Stages}

With a view to effective proceeding for ultimate success in negotiations it may be useful to follow a structured approach. Negotiators generally plan negotiations over six stages namely Preparation, Discussion, Clarification of goals, Negotiate towards a Win-Win outcome, Agreement and Implementation of a course of action (Bookboon, 2012).

Preparation involves accumulating all pertinent facts and figures and information of the situation. When the negotiators are fully conversant with the policies, rules and regulations and also with practices in vogue they would use this information as reference during discussion. When equipped with all the vital information, negotiators are likely to command the discussions with added confidence to put their point across effectively. Better preparation would minimize the prospects of conflicts and disagreements, saving time and energies and the process would roll on with relative ease.

The participants need effective communication skills to put across their point of view convincingly. Inter personnel communication skills are important tools and these can be employed to advance interests. Questioning, clarifying and taking notes, listening attentively and recording points are few of the traits of successful negotiators. During discussion stage each party should have equal opportunity to present their case. 
At this stage, divergent goals, interests and viewpoints from all sides need to be clarified and listed in order of priority. Clarification at this stage would make it possible to identify or establish some common grounds. Clarification is an essential part of the negotiation process and in the absence of clarification of goals; misunderstandings are likely to surface thereby overshadowing the possibility reaching a beneficial outcome.

\section{Negotiations for win-win outcome}

At this stage negotiators are required to negotiate to achieve a win-win outcome. Though it is may not be forthcoming under all circumstances nonetheless it ought to be the ultimate goal of negotiators. With win-win outcome foremost on the minds and priority list of negotiators, compromises and alternate strategies would be explored at this juncture. Since compromises are often positive alternatives so through compromises greater achievements can be made. An agreement is achieved through accommodating, realigning of interests of all sides. When an understanding has been reached and breakthrough is made, the parties concerned agree on modalities and modus operandi. The agreement is ought to be lucid affording understanding about what has been decided thereby effectively preempting the possibility of misinterpretation at implementation stage.

Formally structured approach and different stages of negotiations dilated upon in the preceding paragraphs may not be necessary in informal negotiations. Nevertheless adherence to the basic principles is important and inescapable for successful outcomes of negotiations regardless of their being formal or informal.

\section{Negotiation Styles}

The style exhibited in the course of negotiations is major determinant of the outcome. Negotiation styles or profiles are based on psychological, behavioral characteristics and preferences among other factors like cultural diversity, economic strength, knowledge base, market size and attendant ramifications. Therefore negotiation styles either create value and durable relationships or cause stalemates. The employment of any of these five styles that are avoiding, accommodating, compromising, collaborating and competing is different under different situations and in compatibility with the demands thereof. The specifics of negotiation styles are dilated upon in following paragraphs.

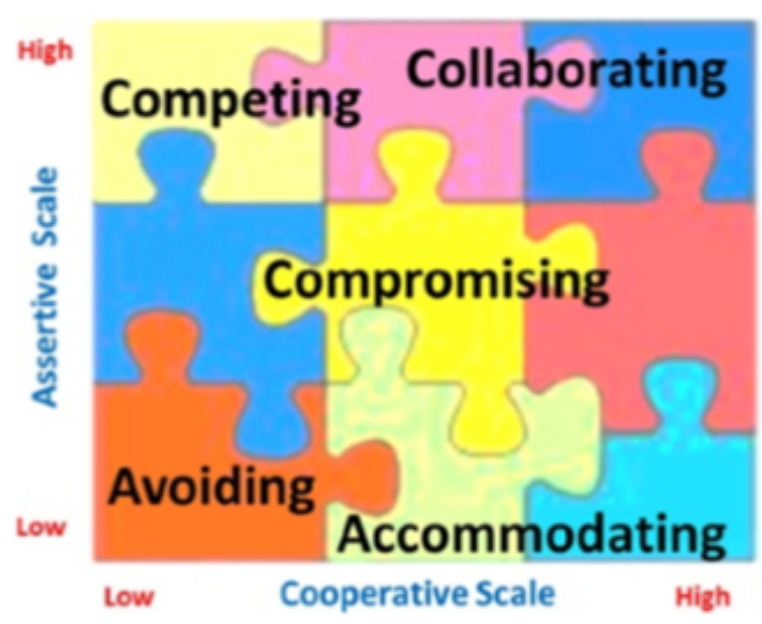

FIGURE 2. Negotiation styles

Negotiators tend to adopt avoiding style when the issue at hand if deferred is unlikely to cast negative bearing on long term relationship. This style is referred as passively aggressive. The technique is to brush the issue under the carpet for present and address it when nerves have soothed and tensions on both sides have subsided (Bookboon, 2012). Thus the strategy of avoiding conflict temporarily and diplomatic maneuvers of dodging and deferring delivers to save a long term relationship from breaking down (McCarthy \& Hay, 2015).

Accommodating style is based on emotions and yearnings to sustain and retain long term relationship at the cost of urgent and immediate interests. Negotiators with accommodating style are sensitive to body language, verbal signals and emotional states of their counterparts (McCarthy \& Hay, 2015). For them relationship is everything and they are willing to forego their immediate interests. They aim at winning hearts and minds and building bridges for sustained relationship (Bookboon, 2012).

Compromising strategy is resorted to by parties concerned to offset time restraints and inadequate preparations coupled with the absence of options or alternatives. This approach is adopted by parties enjoying robust relationship (Bookboon, 2012). Negotiators with this style are good at making quick concessions (McCarthy \& Hay, 2015).

Collaborating style is the best instrument for creating value rather than simply settling for respective gains by the parties concerned. Often referred to as 'expanding the pie', collaborative negotiators are willing to invest more time and energy in finding innovative solutions (McCarthy \& Hay, 2015). Tough problems and intricate issues are best suited to be debated and discussed under collaborative format (Bookboon, 2012). Inculcating collaboration can lead to more sound and positive results. Surprise factor in nego- 
tiations makes Americans to collaborate because it creates room for new openings between competitors/parties. Negative surprise might also impact but positive surprise signals the other party to extend the hand for collaboration (Ben-Yehuda, 2019).

Competing styled negotiators are generally oblivious to long term relationship instead they narrowly focus on short term gains. They are generally ruthless in their pursuit of immediate gains (Bookboon, 2012). They often use whatever power and tactics they can muster, including their personality, position, economic threats, brand strength or size or market share. At its extreme negotiators call their behavior aggressive (McCarthy \& Hay, 2015).

\section{Negotiation Styles used by Americans}

As discussed earlier, negotiation styles are by and large embedded in psychological or behavioral characteristics and preferences among other factors such as cultural diversity, economic strength, knowledge, and market size as their offshoots. Americans are known for their ruthlessly aggressive styles. The most common negotiation style pursued by Americans is competing style.

Americans defines the negotiation style as temperament and influenced by the ability of individual negotiator, personality, the physical situation surrounding the negotiators, emotional, political and cultural factors. There are following characteristics both positive and negative affect the behavior of the United States like impatient, arrogant, listening, insular, legalistic, naïve, friendly, fair, flexible, risk-taker, pragmatic, preparation and cooperation. United States negotiators are the risk taker and they have more authority to make the decision (McDonald, 2001).

The negotiating style of American people is mostly influenced by numerous structural factors such as legal and education system, demographic makeup, economic indicators, governmental structures, geopolitics, and geography. In the United States, the negotiating behavior of people is mostly influenced by two factors which are political system and status. If an issue at stake has political importance at home, they enter into negotiation in their own timeframe and usually press for an early agreement. In table talk, negotiators create association and connection between issues and facts arguing as they are seeking the benefit of a counterparty to reach an agreement through which they can get win-win situation (Census Bureau of United States, 2002).

Americans apply pressure on counterparts because their status and cultural factors give them unparalleled ability to push counterparts towards the agreement. Ameri- can business executives and lawyers use their professional strengths instead of using deception or physical intimidation in the form of shouting. They enter into negotiations in details of the issue at hand and substance. Top level management is also aware of the issues. They focus to fix on preserving the prerogatives of the officials (Census Bureau of United States, 2002). Being nice and warm can not work all time and is not productive approach under some situations. Negotiation is all about persuasion or how to influence others and being nice can backfire because other may want to debate, so it is better to have some sort of pressure on other party (Jeong, Minson, Yeomans, \& Gino, 2019). In the business deals, Americans consider negotiation as a process of problem-solving in which buyer gets the superior position. They primarily focus on short-term objectives during negotiation process. They prefer to use competitive negotiation style. In business dealing process, financial strength and company size play major role in negotiations. Americans may appear more argumentative and competitive but they focus on finding solutions that are acceptable to both parties. It is more appropriate to remain persistent, firm, calm, and show constructive and positive attitude rather than taking things personally (Katz, 2008). With their business oriented approach, American negotiators are forthcoming in exchange of information. They prefer direct approach by making direct requests and putting direct question to find resolution of the issues. They tend to be informal and prefer friendly environment. Their tendency of little adherence to horizontal hierarchy is reflective of their belief in equality of power. They believe in the significance of free communication since its absence does not lend to amicable resolution of interpersonal problems. Americans negotiation style can be best predicted through four factors: observer, controller, disrupter and performer. American negotiators are best in controlling the negotiations to get the outcome in their favor (Kogan, 2019).

Horizontal relationships and equality are strongly valued in the United States; therefore there are fewer adherences to hierarchy because they focus on equality of power. To complete the work more efficiently and effectively, they pass the hierarchy in an organizational structure. Americans consider deal is a deal in the negotiation process and it is a firm commitment. They discuss issues point by point and reach to the overall agreement. Americans consider it as dishonest negotiations when someone expects straightforward negotiation after putting all information at negotiation table (Adachi, 2010). The diagram given below illustrates the Americans negotiation model. 


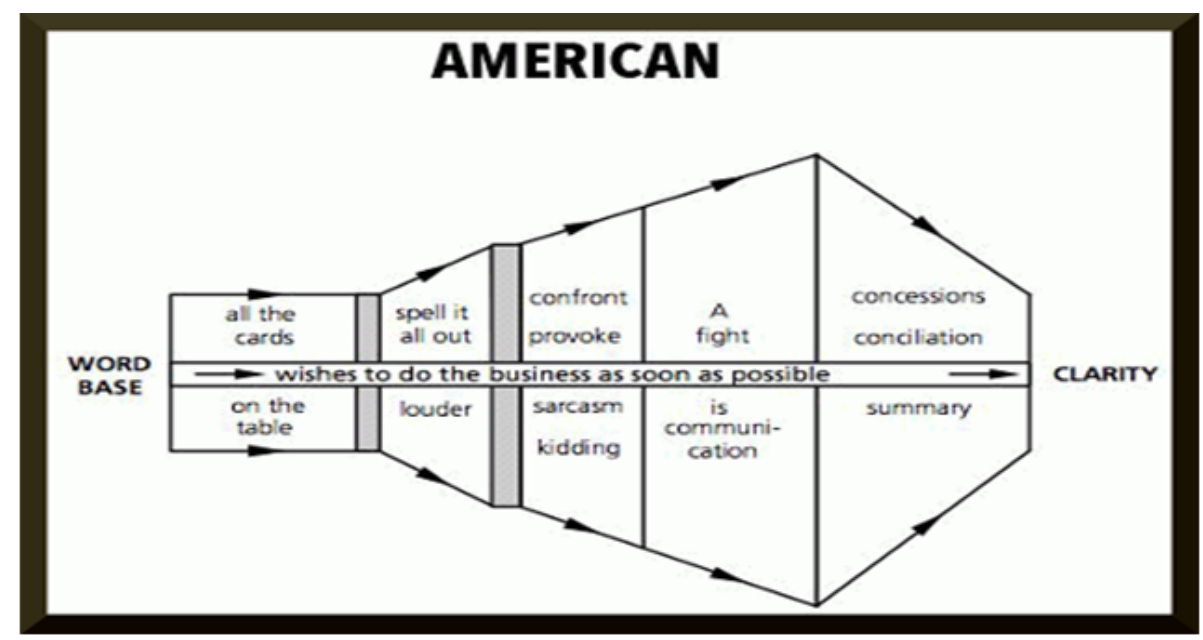

FIGURE 3. American pattern of negotiations

\section{Negotiation Styles Used by Pakistanis}

Pakistan is a polity based on traditions, conventions and social dogmas. Attitudes and behavioral patterns are modeled and shaped by incontrovertible social, cultural and religious values. Therefore, adherents remain bound by them voluntarily or involuntarily and negotiation styles used in Pakistan have the underpinnings of social and cultural norms. Age and social status are respected with little room for humor. Pakistani negotiators attach importance to personal relationships based on mutual respect and mutuality. Their quest for building lasting relationship interferes with their style of negotiation. As a consequence, Pakistanis prefer collaborative style in negotiation. Since collaborative style employs holistic approach to conflict resolution creating value for durable and enduring relationship whereby all parties are in an advantageous position. This truth is supported by the fact that competing and avoiding styles are possibly shunned by the negotiators in Pakistan. Nevertheless, styles of Pakistani negotiators vary under different situations. Compromising and accommodating techniques are also popular with Pakistani negotiators but competing technique remains the last option on the table. They aim to build trust and endeavor to build strong bonds between parties. While negotiating, intermediaries are preferably employed as indirect approach to create bridges and for ground preparation before full steam communications and negotiations begin. Negotiations linger over relatively longer period to the aversion of negotiators from other cultural backgrounds. Confidentiality of special information is used to gain advantage and in negotiation information is rarely shared (Katz, 2008).

In an attempt to maintain holistic approach, Pakistani negotiators seldom proceed in sequence rather they move back and forth to remain within the wider context for comprehensive resolution through multi pronged strategy. It confuses their counterparts from other cultures who are habitual of doing things in linear sequence. They avoid competing technique and employ emotions in making bargains. Their preference in collaborative style is embedded in the belief that through collaborative techniques the interests of all parties are best served since individuals are pooled up into common goals. With a view to contribute toward durability of relationship, Pakistani negotiators resort to compromising techniques (Pakistan Institute for Parlimentary Services, 2016). Geneder matters in negotiations as both genders use different approaches to negotiate effectively. Women use different bargaing strategies to influence negotiation process. Moreover, women's education impacts negotiation process effectively and empowers the decision making process (Shahid, 2017).

Study reveals that collaborative techniques are widely employed in public sector organizations and healthcare centres. In collaborative techniques parties transcend the normal scope and expanse of the issue. Collaborating groups take into focus all the relevant dimensions for discovering new values and innovative solutions to routine issues. In collaboration whole hearted efforts, initiatives and cooperation flow naturally, thus the groups involved in collaborative activities immensely and steadily benefit from collective wisdom with the bonanza of cohesion and further cementing of mutual bonds (Keenan, Cooke, \& Hillis, 1998). Pakistani society is high power distance and it mostly depends on group relationships as per the cultural practices. Pakistan's orientation towards negotiations is medium term mindset. The strength of pakistani negotiators is in building relationships in openess and is emotion- 
ally driven (Naghavi, 2000).

Given the divergence in cultural values, dissimilarities in perceptions and perspectives, different issues between Pakistani and American negotiators are but natural. Pakistani negotiators prefer indirect approach while their counterparts in US are inclined to use direct approach. Likewise Pakistanis rely on assumptions while Americans are realistic. Sometimes Pakistani negotiators while negotiating resort to pressure tactics through recourse to alternate options. Nevertheless, they one way or the other hammer out the solution with amicable outcomes through techniques in accordance with the demands of the circumstances (Salacuse, 1998).

An environment of accommodation, cooperation and sense of belonging at workplace plays significant role for achievement of common goals. When groups interact with positive attitude and supportive approach, efficiency and effectiveness takes big strides. Thus the functioning of the entity will be smoother and output obviously greater. When groups, teams and segments work towards attaining common goals that is recognizing and addressing the interests of each party, then innovative solutions and creative values are easy to shape up. Collaborative techniques work better for promotion of relationship through recognizing, respecting and accommodating the stances, perspectives and interests of all parties. The spirit of accommodation delivers best outcomes (Ali \& Javed, 2015).

Researchers are of the opinion that collaborative, accommodative and compromising approach is closely associated with enhanced effectiveness. Individual interests are sacrificed for collective and organizational interests hence relationship and sense of belonging assumes the priority. Researchers concurrently believe that competing and avoiding leads to low productivity (Gull, Zaidi, et al., 2012). Negotiation skills and conflict resolution leads to effective communication, rationality and builds common sense to resolve issues (Mamatoğlu \& Keskin, 2019).

Analysis provided in this qualitative research paper is based on review of literature conducted by using data and information derived and sifted from books, journals, blogs, institutional websites, and business magazines. The facts and figures thus obtained were employed to elaborate negotiations, its different stages and styles. Negotiation styles used in America and Pakistan were spotlighted. The paper narrowed down its focus upon similarities and dissimilarities between American and Pakistani styles of negotiations.

\section{METHODOLOGY}

This study is based on systematic review to critically analyze and synthesize the past literature on the styles of negotiations prevalent in Pakistan and America. To explore further, the relevant information is derived from the journals, websites, social report of United States, 2012 and research papers published in the past. Meta-analysis is used to pool the results of selected studies.

The search engine of Google scholar was mainly used to consult past studies. Among the databases HEC website was helpful. The papers related to negotiations in general and in particular those focusing on the negotiation styles of Pakistanis and Americans were utilized while papers covering specifically the negotiation styles of other countries were excluded from the review.

\section{DISCUSSION}

Negotiations among humans are as old as humans themselves. Man being social animal cannot live in isolation. The survival of humans is interdependent hence the inception of societies, states and nations and their interaction is the outcome of this interdependence. Disputes, divergence and conflict of interests are also the consequences of interdependence. In a linear process, negotiation is a tool to resolution of conflicts. Therefore negotiations are means to an end.

In recent times negotiations have assumed enhanced significance since the human life has become all the more complex with the shrinkage of time and space. Globalization has virtually reduced the far-flung region into a one whole. Thus advantages of one individual, group, community or society may be the disadvantage of the other. Therefore, the mechanism of negotiations is imperative to resolve issues and conflicts for a peaceful and prosperous whole i.e. the world.

This paper limits its scope to focus on negotiation, its stages, its styles and negotiation styles used by Pakistani and American negotiators. With perfect understanding of negotiations, it becomes easier to understand its styles i.e. avoiding, accommodating, compromising, competing and collaborating. This further makes it easier as when to apply a particular style to the demand of situation and circumstances. Analysts and researchers are unanimous in their opinion that no style is the best but whichever suits to the prevalent conditions and circumstances and whatever can lead to win-win results for all the groups and parties.

When this paper further narrows its focus on Pakistani and American styles of negotiations, it comes to the surface that Americans prefer competing and aggressive techniques of 
negotiations. They exercise pragmatism and tend to be legalistic in regard to the details and sequence. They are insular and poor listeners. They prefer to stay within constitutional and legal framework. They prefer logic, direct approach, exchange of precise information over assumptions. They concurrently believe in short term relationship over long term loyalties and bonds. American negotiators' approach is more utilitarian. Their Pakistani counterparts choose indirect approach, prefer accommodating, collaborative and compromising styles to retain and maintain long term relationships. They employ assumptions, emotions and intermediaries. They use personal relationships to influence negotiations. The single most preferred style with Pakistani negotiators is collaborative style while their American counterparts seem wedded to competing style. The only similarities between American and Pakistani negotiators are that they agree on mutual concessions so as to reach a win-win solution and minimal use of avoiding style.

\section{IMPLICATIONS}

While referring to the negotiating styles of Pakistanis and Americans, it is recommended that following may be considered:-

- Competing Style is the most preferred style with American negotiators.

- Americans employ aggressive techniques while negotiating.

- American negotiators are direct and meticulous.

- Americans negotiators are focused on short term relationship.

- They are insular about other cultures.

- Collaborative style is the most preferred one with Pakistani negotiators.

- Pakistanis employ compromising and accommodating styles as second best.

- They prefer long term relationship and loyalties over short term bonds.

- They use emotions and assumptions while negotiating.

- They use intermediaries and indirect approach.

- Their next preferred Style is compromising.

- They have respect for age and status.

- They use personal relationships to influence negotiations.

\section{CONCLUSION}

The role of negotiations is doubtlessly important and it shall continue to remain significant as long as mankind populates the planet earth rather it shall assume added importance since human life is becoming more complex and interdependent. Contemporary and future negotiators shall need to refine their negotiating skills in terms of better preparation, pooling information, clarifying objectives, spirit of accommodation and belief in mutuality. No negotiation style is ultimate; it is only the outcome that makes it best or worst. It is only the circumstances and the end result that determines the success or failure of a particular negotiation style. A skilled negotiator is one who has his finger on the pulse of time and circumstances.

Negotiators interacting with Pakistani and their American counterparts are to be cognizant of the fact that Americans build on short term relationship. They prefer competing style and aggressive techniques. Contrarily Pakistani negotiators prefer collaborative style and work to build lasting bonds and loyalties.

\section{LIMITATIONS AND RECOMMENDATIONS}

There is always room of improvement in every research paper. Likewise, this paper can be improved by adding more literature review. The major limitation of this paper is that due to time constraint other techniques such as questionnaires, focus groups and interviews could not be used in order to explore the negotiation styles of both countries. Lack of time kept the study limited to exploration of variable in literature review.

\section{REFERENCES}

Adachi, Y. (2010). Business negotiations between the Americans and the Japanese. Global Business Languages, 2(4), 18-30.

Ali, A., \& Javed, B. (2015). The models of conflict and managerial leadership styles of managers. Global Business and Management Research: An International Journal, 7(2), 56-60.

Ben-Yehuda, T. L. (2019). When surprise is a god negotiation tactic. Cambridge, MA: Harvard Business Review Press.

Bookboon. (2012). The 5 stages of a successful negotiation. Retrieved from https://bit. ly/3dFYfBR

Caputo, A., Ayoko, O. B., Amoo, N., \& Menke, C. (2019). The relationship between cultural values, cultural intelligence and negotiation styles. Journal of Business Research, 99, 23-36. doi:https://doi.org/10.1016/j.jbusres.2019.02.011

Census Bureau of United States. (2002). Statistical abstract of the United States: 2002. Retrieved from https://bit.1y/ 31nZi6V

Fisher, R., Ury, W. L., \& Patton, B. (2011). Getting to yes: Negotiating agreement without giving in. New York, NY: Penguin. 
Gull, S., Zaidi, S. F. B., et al. (2012). Impact of conflict management styles on team effectiveness in textile sector of Pakistan. International Journal of Business and Management, 7(3), 219-230. doi:https://doi.org/10.5539/ijbm.v7n3p219

Hüffmeier, J., Zerres, A., Freund, P. A., Backhaus, K., Trötschel, R., \& Hertel, G. (2019). Strong or weak synergy? Revising the assumption of team-related advantages in integrative negotiations. Journal of Management, 45(7), 2721--2750. doi:https://doi.org/10.1177/0149206318770245

Jeong, M., Minson, J., Yeomans, M., \& Gino, F. (2019). Being nice in a negotiation can backfire. Harvard Business Review, 45(2), 45-50.

Katz, L. (2008). Negotiating international business-Pakistan. Retrieved from https://bit. ly/3dEGZwZ

Keenan, G. M., Cooke, R., \& Hillis, S. L. (1998). Norms and nurse management of conflicts: Keys to understanding nurse physician collaboration. Research in Nursing \& Health, 21(1), 59-72. doi:https://doi.org/10.1002/(sici)1098-240x(199802) 21:1<59::aid-nur7>3.0.co;2-s

Kogan, E. B. (2019). Art of the power deal: The four negotiation roles of Donald J. Trump. Negotiation Journal, 35(1), 65-83. doi:https://doi.org/10.1111/nejo.12265

Lewicki, R., Saunders, D., \& Barry, B. (2006). Negotiation. Boston, MA: McGraw-Hill.

Mamatoğlu, N., \& Keskin, S. (2019). Effective conflict resolution and negotiation skills scale. Journal of Faculty of Letters/Edebiyat Fakultesi Dergisi, 36(1), 45-60.

Manager, D. (2017). The aesthetic dimension of decision making: A case study of a German software company. International Journal of Humanities, Arts and Social Sciences, 3(5), 223-230. doi:https://doi.org/10.20469/ijhss.3.20005-5

McCarthy, A., \& Hay, S. (2015). Advanced negotiation techniques. London, UK: Springer.

McDonald, J. W. (2001). An American's view of U.S. negotiating style. Retrieved from https://unc. live/3g38rWK

Mitchell, J. B. (2020). Research: How to build trust with business partners from other cultures. Retrieved from https:// bit.1y/3i5dGap

Naghavi, M. M. (2000). Negotiaiting with managers from Pakistan. The palgrave handbook of cross-cultural business negotiation. London, UK: Sage Publications.

Pakistan Institute for Parlimentary Services. (2016). Conflict resolution and negotiation skills. Retrieved from https:// bit.ly/2NDZeI9

Pan, S., \& Lu, L. (2019). A preliminary study on the cause of conflicts in multidisciplinary collaboration. Journal of Advances in Humanities and Social Sciences, 5(1), 44-53. doi:https://doi.org/10.20474/jahss-5.1.5

Raditya, W. (2018). Influnce of role conflict, authorities of jobs in employee work satisfaction. International Journal of Business and Economic Affairs, 3(4), 160-170. doi:https://doi.org/10.24088/ijbea-2018-34003

Salacuse, J. W. (1998). Ten ways that culture affects negotiating style: Some survey results. Negotiation Journal, 14(3), 221-240. doi:https://doi.org/10.1111/j.1571-9979.1998.tb00162.x

Shahid, U. (2017). Describing determinants of negotiation and bargaining to access and utilize resource including health among immigrant pakistani women in us. International Journal of Gender and Women's Studies, 6(1), 34-50. doi: https://doi.org/10.15640/ijgws.v6n1a1

Singh, B. (2008). Managing conflict and negotiation. New Dehli, India: Excel Books India.

Ury, W. (1993). Getting past no: Negotiating your way from confrontation to cooperation. New York, NY: Bantam.

Ury, W. (2007). The power of a positive no: How to say no and still get to yes. New York, NY: Bantam. 